\title{
Consumo de tabaco en poblaciones estigmatizadas
}

\section{Tobacco consumption in stigmatized populations}

LILIANA FERNÁNDEZ T., MD. ${ }^{(1)}$

El papel del cigarrillo como causa de múltiples enfermedades, está suficientemente establecido tanto en los países desarrollados como en los emergentes, y es la principal causa de muerte prevenible prácticamente en todas las naciones (1). En los Estados Unidos se trabaja activamente en campañas para controlar su consumo, de tal manera que ha habido una disminución del porcentaje de fumadores, que ha pasado desde el 42\% en 1965 hasta al rededor del $18 \%$ en 2012. Sin embargo la guerra contra el tabaco no se ha ganado todavía, pues aún es la más causa de muerte prevenible más importante y hay más de 42 millones de adultos y 3 millones de niños fumadores en dicho, situación también que se refleja en Colombia y el resto de países de Latinoamérica.

De otra parte, existe evidencia actual que indica que la composición de los cigarrillos ha cambiado respecto a los elaborados en los años 50, aumentando el riesgo de los fumadores de desarrollar cáncer pulmonar y enfermedad pulmonar obstructiva crónica. Por tanto, el riesgo de morir por fumar cigarrillo es ahora mayor que hace 50 años (2). En este numero de la revista se publica el artículo de Bravo y colaboradores (3), quienes hacen una interesante revisión de la literatura en cuanto al uso del tabaco en poblacio- nes estigmatizadas, con razones culturalmente poderosas de exclusión social, como son los enfermos mentales con esquizofrenia, los homosexuales, los reclusos y los trabajadores sexuales, en quienes encontraron tasas elevadas de consumo, hecho que forma parte de otros rasgos del estilo de vida poco saludable de estas poblaciones y por ende las hace más vulnerables a morbilidad y mortalidad. Identifican, además, limitaciones en su estudio pues la búsqueda de literatura se restringió a una sola base de datos si bien de todas hacen evidente la poca atención que reciben en prevención ciertos grupos poblacionales.

Así mismo, en este número encontrarán una serie de artículos de gran utilidad, que esperamos llenen las expectativas de todos ustedes.

\section{Bibliografía}

1. La Torre Guiseppe, Ferketich A, Grassi MC. Tobacco somoking: the evidence from prevention and cessation. Biomed Res Int. 2014;2014:894208. doi:10.1155 /2014/894208.

2. Schroeder SA, Koh HK. Tobacco control 50 years after the 1964 surgeon general's report. JAMA. 2014;311(2):141-3.

3. Bravo A, Cabrera MC, Gómez LF, Pinto AF, Rosselli D. Consumo de tabaco en poblaciones estigmatizadas: una revisión de la literatura en Pubmed. Rev Colomb Neumol. 2015;27(3):1-7.
${ }^{(1)}$ Medicina Interna, Neumología, Neumología Intervencionista, Línea del Investigación Biomédica en Tórax, Fundación Valle del Lili. Profesora Clínica Asociada, Facultad de Ciencias de la Salud, Universidad Icesi. Cali-Colombia. Correspondencia: Liliana Fernández T., correos electrónicos: lfernandez@fcvl. org, lilianafernandeztrujillo@gmail.com Recibido: 30/07/15. Aceptado: 05/08/15. 